\title{
PELET REJECT INDUSTRI KERTAS SEBAGAI BAHAN BAKAR BOILER
}

\author{
Yusup Setiawan ${ }^{1}$, Sri Purwati, Aep Surachman, Reza Bastari I. W., Henggar Hardiani \\ Balai Besar Pulp dan Kertas, Jalan Raya Dayeuhkolot No. 132, Bandung \\ ${ }^{1}$ yusupsetiawan60@yahoo.com
}

Diterima : 24 April 2014, Revisi akhir : 29 Oktober 2014, Disetujui terbit : 3 November 2014

\section{REJECT PELLET OF PAPER MILL AS BOILER FUEL}

\begin{abstract}
Paper mill using recycle fiber as raw material produces reject containing fiber and plastic. The reject was identified by means of sorting. Reject pellet was prepared by drying, followed by shredding, and pellets molding. It was analyzed for its proximate composition (moisture, ash, volatile matter and fixed carbon). Calorific value, sulfur content, ash mineral content, and ash fusion temperatures were also tested. The results showed that reject consists of $50.75 \%$ fiber and $49.25 \%$ plastic of which is $>99 \%$ High Density Polyethylene (HDPE). Reject contains a high calorific value of about $7000 \mathrm{cal} / \mathrm{g}$ which could potentially be used as fuel. Coal boiler fuel containing 5-50\% reject pellet shows no indication of slagging and fouling in the boiler.
\end{abstract}

Keywords: reject, pellet, coal, calorific value, fuel

\begin{abstract}
ABSTRAK
Industri kertas berbahan baku kertas bekas menghasilkan reject yang mengandung serat dan plastik. Reject diidentifikasi komponennya dengan cara pemilahan. Proses pembuatan pelet dari reject industri kertas terdiri dari proses pengeringan, pencacahan, dan pencetakan pelet. Pelet reject dianalisis proksimat (kadar air lembap, kadar abu, kadar zat terbang (volatile matter) dan karbon padat (fixed carbon). Nilai kalor, kadar sulfur, kadar mineral abu, dan suhu fusi abu (Ash Fusion Temperature) pelet reject juga diuji. Hasil menunjukkan bahwa komponen reject terdiri dari serat 50,75\% dan plastik 49,25\% dengan kandungan plastik jenis High Density Polyethylene (HDPE) lebih dari 99\%. Nilai kalor pelet reject sekitar 7.000 kalori/gram. Hal ini menunjukkan potensi pelet reject sebagai bahan bakar campuran batubara. Penambahan pelet reject sebanyak $5-50 \%$ ke dalam batubara dapat digunakan sebagai bahan bakar boiler tanpa menyebabkan indikasi terjadinya slagging dan fouling di dalam boiler.
\end{abstract}

Kata kunci: reject, pelet, batubara, nilai kalor, bahan bakar

\section{PENDAHULUAN}

Industri kertas yang memproduksi kertas tuliscetak, koran, tisu, lainer-medium, dan karton banyak yang menggunakan kertas bekas jenis Old News Paper (ONP), Old Corrugated Carton (OCC) atau campuran sebagai bahan bakunya. Konsumsi kertas bekas sebagai bahan baku industri kertas terus meningkat sejak tahun 2000. Pada tahun 2011, konsumsi kertas bekas oleh industri kertas di Indonesia sekitar 1.600.000 ton (Balai Besar Pulp dan Kertas, 2012).

Dalam proses produksinya, selain menghasilkan kertas, industri kertas menghasilkan produk samping berupa reject yang jumlahnya cukup banyak sekitar $5-25 \%$ w/w. Sebagian besar komponen reject industri kertas tersebut terdiri dari bundel serat, foil dan potongan plastik yang banyaknya tergantung pada kualitas kertas bekas yang digunakan sebagai bahan baku. Reject umumnya memiliki nilai kalor tinggi dengan kandungan abu yang rendah (Gavrilescu, 2008; Oudi dkk., 2012). Perubahan bentuk reject dari bentuk ruah menjadi bentuk pelet merupakan suatu metode solidifikasi reject untuk mengkonversi reject yang mudah terbakar menjadi bahan 
bakar (Nichols dan Flanders, 1994; Kuik, 2006). Keuntungan reject dalam bentuk pelet antara lain ukurannya menjadi seragam, jumlah debunya sedikit, dan memudahkan dalam penyimpanan dan pengangkutan (Thacker, 2000; www. pelletstove.com). Penggunaan pelet reject pabrik kertas sebagai bahan bakar untuk memproduksi energi saat ini telah diterapkan di Jepang dan banyak negara Eropa (Gavrilescu, 2008; www. jrpf.g.jp). Saat ini, industri yang memproduksi pelet sebagai bahan bakar berkembang cukup pesat karena dipandang sebagai bahan bakar masa depan (Nobuyuki dkk., 2011).

Pengelolaan reject industri kertas yang diterapkan saat ini oleh industri kertas di Indonesia, umumnya dibuang keluar pabrik melalui jasa pihak lain atau mengurangi jumlah ruah reject dengan membakarnya di insinerator. Pengolahan reject industri kertas menjadi bentuk pelet sebagai bahan bakar boiler untuk mengurangi pemakaian batubara atau bahan bakar fosil lainnya belum ada yang melakukannya. Bila reject dibuat dalam bentuk pelet dan digunakan sebagai bahan bakar yang dicampurkan dengan batubara, maka mempunyai beberapa keuntungan untuk industri kertas antara lain dapat mengurangi biaya penanganan limbah padat yang selama ini diangkut keluar pabrik menggunakan jasa pihak ketiga, meningkatkan kebersihan dan citra pabrik kertas tersebut, dan mengurangi biaya pengadaan batubara sebagai bahan bakar boiler.

Untuk mengetahui seberapa jauh potensi reject industri kertas sebagai bahan bakar, identifikasi komponen reject, proses pembuatan pelet reject, dan karakterisasi pelet reject telah dilakukan dan hasil kajiannya disajikan dalam makalah ini.

\section{BAHAN DAN METODE}

\section{Bahan}

Bahan yang digunakan adalah reject dan batubara sebagai pembanding diambil dari industri kertas yang memproduksi kertas corrugating medium dan kraft liner berbahan baku kertas bekas. Reject masih mengandung kadar air sekitar $40-50 \%$. Batubara yang digunakan sebagai bahan bakar boiler pabrik kertas ini juga digunakan sebagai pencampur dan pembanding.

\section{Metode}

Reject untuk percobaan diambil dari industri kertas yang pengurangan kadar air reject menggunakan mesin peras hidrolik. Pengurangan kadar air reject selanjutnya dilakukan di laboratorium Balai Besar Pulp dan Kertas (BBPK) dengan menggunakan panas sinar matahari sampai mengandung kadar air $<10 \%$ yang sudah dipisahkan dari kandungan bahan logam dan siap untuk dirajang di mesin perajang reject. Identifikasi jenis plastik yang terkandung dalam reject dilakukan berdasarkan berat jenis (Tabel 1) dan uji warna bakar (www. monroecounty.gov). Gambar 1 menunjukkan diagram alir uji pemisahan jenis-jenis plastik. Reject disortir dan dipilah-pilah berdasarkan jenisnya untuk identifikasi komponen reject. Reject kering dirajang/dicacah dengan menggunakan mesin pencacah yang mempunyai pisau pencacah dengan lubang screen berukuran sekitar $4 \mathrm{~mm}$ untuk keluaran hasil pencacahannya. Cacahan reject selanjutnya

Tabel 1. Berat Jenis Bahan Plastik (www.monroecounty.gov.)

\begin{tabular}{lc}
\hline \multicolumn{1}{c}{ Bahan } & Berat Jenis $(\mathrm{g} / \mathrm{mL})$ \\
\hline Air & 1,00 \\
\hline 1. Polyethylene Terephthalate (PET) & $1,38-1,39$ \\
2. High Density Polyethylene (HDPE) & $0,95-0,97$ \\
3. Polyvinyl Chloride (PVC) & $1,16-1,35$ \\
4. Low Density Polyethylene (LDPE) & $0,92-0,94$ \\
5. Polypropylene (PP) & $0,90-0,91$ \\
6. Polystyrene (PS) & $1,05-1,07$ \\
\hline
\end{tabular}


dibuat pelet menggunakan mesin pelet yang mempunyai ukuran lubang cetakan pelet 10 $\mathrm{mm}$. Pelet reject yang dihasilkan berdiameter 10 $\mathrm{mm}$ dengan panjang sekitar $10-15 \mathrm{~mm}$.

\section{Analisis Bahan dan Produk}

Analisis bahan dan produk mengacu kepada analisis batubara menggunakan metode uji ASTM yang meliputi analisis proksimat (kadar air lembap, kadar abu, kadar zat terbang (Volatile Matter), dan karbon padat (Fixed Carbon)), nilai kalor, kadar sulfur, dan suhu fusi abu (Ash Fusion Temperature).Kadar mineral abu dianalisis menggunakan Atomic Absorption Spectroscopy (AAS)

\section{HASIL DAN PEMBAHASAN}

\section{Identifikasi Komponen Reject}

Hasil identifikasi menunjukkan bahwa komponen reject sebagian besar terdiri dari serat berupa potongan kertas sebanyak 50,75\% (Gambar 2a), plastik berupa lakban dan lembaran sebanyak 49,25\% (Gambar 2b.). Reject juga mengandung komponen logam yang berasal dari kawat tetapi jumlahnya sedikit sekali.

Dari hasil uji reject di dalam air, terdapat reject yang mengapung dan tenggelam. Banyaknya jumlah reject yang mengapung adalah sekitar $82,33 \%$ dan yang tenggelam sekitar $17,67 \%$. Dari uji reject yang mengapung dalam air

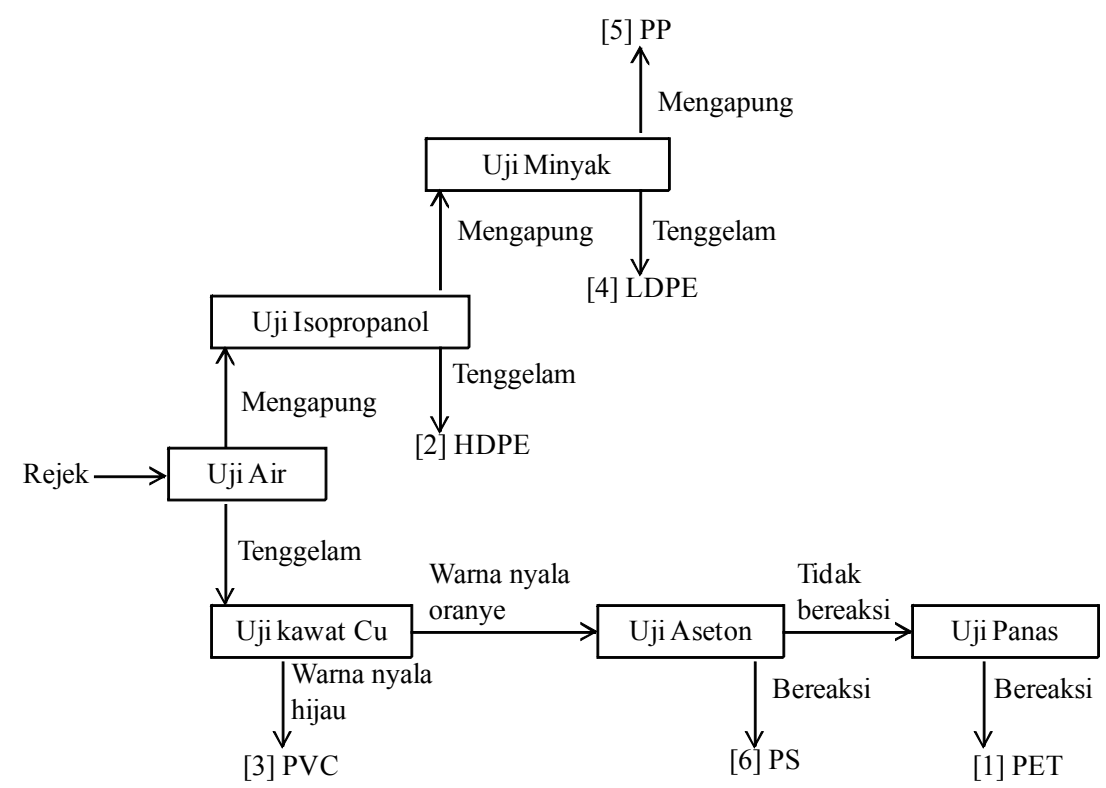

Gambar 1. Diagam Alir Uji Pemisahan Jenis-Jenis Plastik (www.monroecounty.gov)

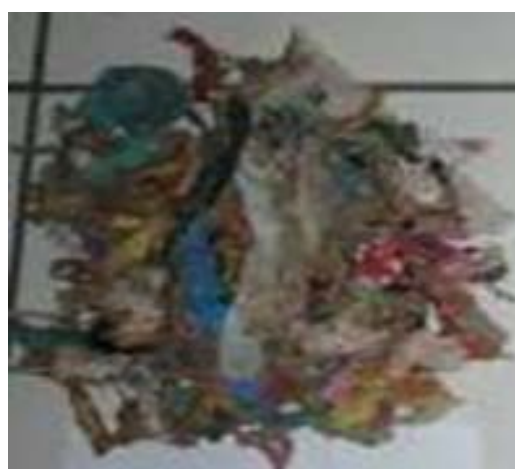

(a). Serat (Potongan Kertas)

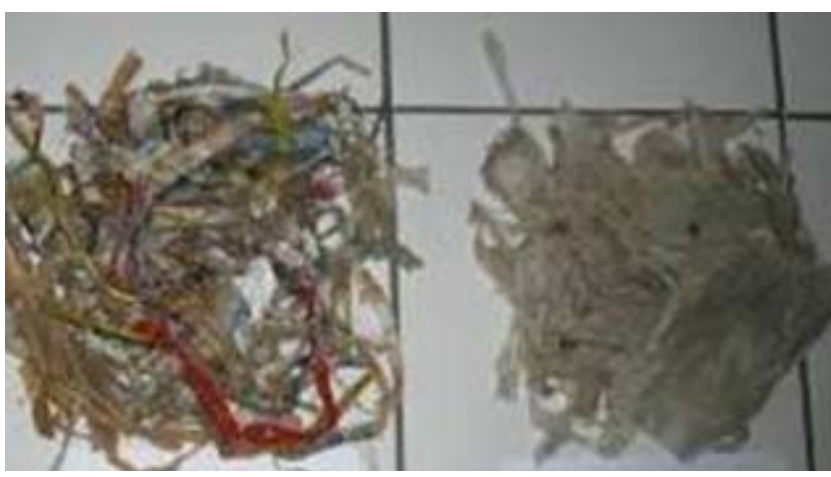

(b). Plastik Lakban dan Lembaran

Gambar 2. Komponen Terbanyak dalam Reject 
selanjutnya diuji dalam larutan isopropanol. Hasil menunjukkan bahwa sebagian besar (lebih dari $99 \%$ ) reject tenggelam dalam isopropanol dan yang mengapung hanya sebagian kecil saja $(<1 \%)$.

Dari uji isopropanol ini, komponen reject yang tenggelam didominasi oleh plastik jenis HDPE. Sedangkan yang mengapung dalam isopropanol adalah jenis plastik LDPE dan/atau PP. Reject yang tenggelam selanjutnya diuji nyala menggunakan batang kawat $\mathrm{Cu}$. Hasil pengamatan menunjukkan ada kecenderungan reject yang tenggelam ini didominasi oleh bahan serat. Hal ini terlihat pada saat percobaan uji nyala menggunakan batang kawat $\mathrm{Cu}$, bahan yang tenggelam ini sulit sekali menempel dengan sendirinya pada kawat $\mathrm{Cu}$ panas. Pada akhirnya untuk mengetahui warna nyala bakar, bahan yang tenggelam dalam air tersebut ditempelkan pada kawat $\mathrm{Cu}$ dan hasil nyala pembakarannya berwarna oranye. Warna nyala bakar bahan-bahan tersebut berbeda sekali dengan nyala bakar dari plastik Poly Vynil Chloride (PVC) yang berwarna hijau. Dari hasil uji nyala reject, kandungan jenis plastik PVC dalam reject kemungkinannya ada walaupun dalam jumlah yang sangat rendah. Karena reject ini mengandung limbah plastik yang mengandung perekat dari plastik selotif/ lakban, ada kemungkinan limbah plastik yang berperekat tersebut menempel pada plastik lainya yang berat jenisnya lebih rendah dari air sehingga terbawa mengapung.

\section{Pembuatan Pelet Reject}

Percobaan pembuatan pelet dari reject telah dilakukan dengan variasi kadar air. Dari hasil percobaan skala prototip menunjukkan bahwa pembuatan pelet dengan kadar air bahan $<15 \%$ dapat menghasilkan pelet yang kompak tidak mudah pecah kembali (Gambar 3).

Hal ini dapat disebabkan karena reject mengandung bahan plastik yang selama pembuatan pelet dalam mesin pelet timbul panas yang menyebabkan suhu pada pembuatan pelet mencapai $80-90^{\circ} \mathrm{C}$. Tingginya suhu ini menyebabkan plastik menjadi lunak dan bersifat sebagai bahan perekat yang membantu terjadinya proses solidifikasi reject. Sedangkan bila kadar air bahan reject $>15 \%$, pelet yang dihasilkan mudah pecah kembali karena penguapan air lebih dominan dari pada pelunakan plastik sehingga tidak membentuk rekatan pelet yang dihasilkan.

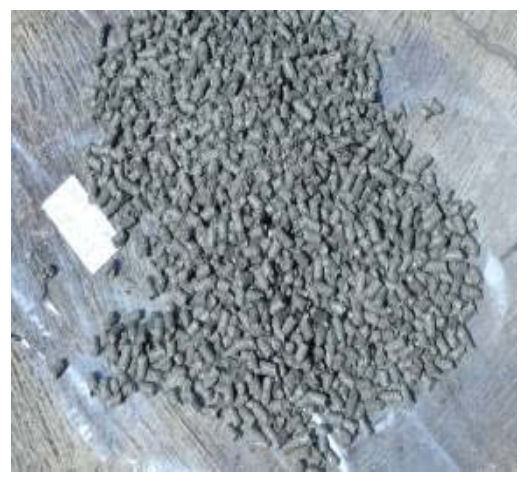

Gambar 3. Pelet Reject

\section{Karakterisasi Pelet Reject}

a. Analisis Proksimat, Nilai Kalor dan Kadar Sulfur

Pelet reject, campuran reject dan batubara, dan batubara sebagai pembanding dilakukan analisis dengan parameter seperti analisis batubara meliputi analisis proksimat (kadar air, kadar abu, kadar zat terbang, kadar karbon padat), nilai kalor, kadar mineral abu dan diuji suhu pelelehan Abu (AFT). Hasil analisis proksimat, nilai kalor dan kadar sulfur dari pelet reject, batubara dan campurannya ditunjukkan pada Tabel 2.

Tabel 2 menunjukkan bahwa kadar air batubara lebih besar dari kadar air pelet reject dan campurannya. Batubara memiliki kadar abu yang lebih tinggi daripada pelet reject atau campurannya. Kadar abu pelet reject $(5,59 \%)$ lebih rendah dibandingkan dengan kadar abu dari batubara $(12,94 \%)$ yang digunakan sebagai bahan bakar industri kertas. Hal ini menunjukkan bahwa penambahan pelet reject ke dalam batubara dapat menurunkan kadar abu bakar boiler. Kadar zat terbang dari batubara sekitar $(37,89 \%)$ jauh lebih rendah dari pelet reject, atau campurannya. Pelet reject memiliki kadar zat terbang tertinggi yaitu $86,32 \%$. Tingginya kadar zat terbang pelet reject akan meningkatkan kadar zat terbang campurannya dengan batubara. Kadar karbon padat dari pelet reject, dan campurannya dengan batubara semuanya dibawah kadar karbon padat batubara sendiri $(38,48 \%)$. Kadar karbon padat pelet reject jauh lebih rendah dari pada batubara. Tinggi rendahnya kadar parameter karbon padat dan kadar zat terbang bahan bakar sangat berpengaruh sekali terhadap sifat pengapian pada saat pembakaran bahan bakar dan terhadap 
Tabel 2. Hasil Analisis Proksimat, Nilai Kalor dan Kadar Sulfur Pelet Reject, Batubara dan Campurannya

\begin{tabular}{|c|c|c|c|c|c|c|c|c|}
\hline \multirow[b]{2}{*}{ No } & \multirow[b]{2}{*}{ Bahan } & \multicolumn{4}{|c|}{ Analisis Proksimat (\%) } & \multirow{2}{*}{$\begin{array}{l}\text { Rasio } \\
\text { bahan } \\
\text { bakar }\end{array}$} & \multirow{2}{*}{$\begin{array}{c}\text { Nilai Kalor } \\
\text { (Kalori/ } \\
\text { gram) }\end{array}$} & \multirow{2}{*}{$\begin{array}{c}\text { Sulfur } \\
(\%)\end{array}$} \\
\hline & & $\begin{array}{c}\text { Air } \\
\text { lembap }\end{array}$ & $\mathrm{Abu}$ & $\begin{array}{c}\text { Zat } \\
\text { Terbang }\end{array}$ & $\begin{array}{c}\text { Karbon } \\
\text { padat }\end{array}$ & & & \\
\hline 1 & Pelet reject & 2,47 & 6,70 & 86,32 & 4,51 & 0,085 & 7.002 & 0,15 \\
\hline 2 & $\begin{array}{l}\text { Batubara } 95 \%+ \\
\text { Pelet reject } 5 \%\end{array}$ & 10,18 & 13,60 & 39,61 & 36,61 & 0,924 & 5.314 & 0,74 \\
\hline 3 & $\begin{array}{l}\text { Batubara } 90 \%+ \\
\text { Pelet reject } 10 \%\end{array}$ & 10,46 & 12,35 & 41,70 & 35,49 & 0,851 & 5.435 & 0,68 \\
\hline 4 & Batubara & 10,69 & 12,94 & 37,89 & 38,48 & 1,016 & 5.240 & 0,80 \\
\hline
\end{tabular}

banyaknya jumlah karbon yang terbakar. Perbandingan kadar karbon padat terhadap kadar zat terbang disebut dengan rasio bahan bakar (kadar karbon padat/kadar zat terbang). Bila rasio bahan bakar nilainya $<1,2$ akan menghasilkan pengapian pembakaran bahan bakar yang bagus dengan kecepatan pembakaran yang meningkat. Sebaliknya bila rasio bahan bakar $>1,2$ akan menyebabkan banyak karbon yang tidak terbakar (www.fortunacoal.com; imambudiraharjo. wordpress.com). Hasil perhitungan rasio bahan bakar pelet reject, campurannya dan batubara nilainya $<1,2$. Hal ini menunjukkan bahwa pada proses pembakaran bahan bakar pengapiannya akan bagus. Tabel 2 menunjukkan bahwa rasio bahan bakar pelet yang terbuat dari reject dan campurannya nilainya lebih kecil daripada batubara. Hal ini akan menyebabkan bahwa sifat pengapian dan kecepatan pembakarannya akan lebih bagus dan lebih cepat daripada batubara. Dengan demikian penambahan pelet reject ke dalam batubara akan sangat berguna sekali terutama pada saat pembakaran awal. Manfaat yang diperoleh untuk menghidupkan boiler yaitu penyalaan batubara akan lebih cepat dan singkat (Miles, dkk., 1995; www.fortunacoal. com; imambudiraharjo.wordpress.com).

Tabel 2 memperlihatkan bahwa pelet reject memiliki nilai kalor yang lebih tinggi dari nilai kalor batubara yang digunakan sebagai bahan bakar di industri kertas. Sebaliknya kadar sulfur pelet reject lebih rendah dari pada batubara. Hal ini menunjukkan bahwa penambahan pelet reject ke dalam batubara akan meningkatkan nilai kalor bahan bakar boiler. Selain itu kadar sulfur bahan bakar boiler akan menurun sehingga akan menyebabkan penurunan kadar $\mathrm{SO}_{2}$ emisi boiler.

\section{b. Kadar Mineral Abu}

Untuk mengetahui sejauh mana prospeknya penambahan pelet reject sebagai bahan bakar campuran batu bara, perlu dilakukan pengujian kadar mineral abunya. Nilai dari kadar mineral abu ini sangat berguna sekali untuk mengevaluasi bahan bakar terhadap potensi terjadinya proses slagging dan fouling di dalam boiler pada saat proses pembakaran. Slagging dan fouling adalah fenomena menempel dan menumpuknya abu bahan bakar yang melebur pada pipa penghantar panas (heat exchanger tube) ataupun dinding boiler. Kedua fenomena ini sangat serius karena dapat memberikan dampak besar pada operasional boiler, seperti masalah penghantaran panas, penurunan efisiensi boiler, dan tersumbatnya pipa. Fenomena menempelnya abu ini dipengaruhi oleh kandungan mineral abu $\left(\mathrm{Na}_{2} \mathrm{O}, \mathrm{K}_{2} \mathrm{O}, \mathrm{Fe}_{2} \mathrm{O}_{3}\right.$ dan $\left.\mathrm{CaO}\right)$, dan suhu fusi abu (ash fusion temperature). Keberadaan senyawa $\mathrm{Na}_{2} \mathrm{O}$ dan $\mathrm{K}_{2} \mathrm{O}$ dalam abu akan membentuk senyawa yang memiliki titik lebur rendah bila berikatan dengan unsur yang lain. Meningkatnya kecenderungan slagging akan diikuti juga oleh meningkatnya kecenderungan fouling, sesuai dengan kadar alkali abu. Standar kualitas batubara yang digunakan di Jepang dan pembuat boiler di Eropa dan Amerika yang mempersyaratkan kadar $\mathrm{Na}_{2} \mathrm{O}<3 \%$, kadar total alkali $\left(\mathrm{Na}_{2} \mathrm{O}\right.$ dan $\left.\mathrm{K}_{2} \mathrm{O}\right)$ $<3 \%$, kadar $\mathrm{CaO}<20 \%$, dan kadar $\mathrm{Fe}_{2} \mathrm{O}_{3}<15 \%$ (Hatt, 1990; Maphala, 2008; www.venus-boiler. com/; Hiltunen dkk., 2008).

Hasil analisis kadar mineral abu pelet reject, batubara dan campurannya ditunjukkan pada Tabel 3. Tabel 3 menunjukkan bahwa batubara yang digunakan sebagai bahan bakar boiler di 
industri kertas mengandung kadar $\mathrm{Na}_{2} \mathrm{O}=0,97 \%$, kadar total alkali $\left(\mathrm{Na}_{2} \mathrm{O}\right.$ dan $\left.\mathrm{K}_{2} \mathrm{O}\right)=2,59 \%$, kadar $\mathrm{CaO}=2,25 \%$, dan kadar $\mathrm{Fe}_{2} \mathrm{O}_{3}=8,01 \%$ telah memenuhi persyaratan. Adapun untuk pelet yang terbuat dari reject mengandung kadar $\mathrm{Na}_{2} \mathrm{O}=0,72 \%$, kadar total alkali $\left(\mathrm{Na}_{2} \mathrm{O}\right.$ dan $\left.\mathrm{K}_{2} \mathrm{O}\right)=1,29 \%$, kadar $\mathrm{CaO}=21,5 \%$, dan kadar $\mathrm{Fe}_{2} \mathrm{O}_{3}=33,34 \%$, parameter $\mathrm{CaO}$ dan $\mathrm{Fe}_{2} \mathrm{O}_{3}$ nya tidak memenuhi persyaratan. Sedangkan untuk campuran $90 \%$ batubara dan $10 \%$ pelet reject mengandung kadar $\mathrm{Na}_{2} \mathrm{O}=0,70 \%$, kadar total alkali $\left(\mathrm{Na}_{2} \mathrm{O}\right.$ dan $\left.\mathrm{K}_{2} \mathrm{O}\right)=2,88 \%$, kadar $\mathrm{CaO}=$ $3,91 \%$, dan kadar $\mathrm{Fe}_{2} \mathrm{O}_{3}=10,49 \%$, dan campuran $50 \%$ batubara dan $50 \%$ pelet reject mengandung kadar $\mathrm{Na}_{2} \mathrm{O}=0,49 \%$, kadar total alkali $\left(\mathrm{Na}_{2} \mathrm{O}\right.$ dan $\left.\mathrm{K}_{2} \mathrm{O}\right)=1,16 \%$, kadar $\mathrm{CaO}=11,03 \%$, dan kadar $\mathrm{Fe}_{2} \mathrm{O}_{3}=8,75 \%$ yang mana semua parameternya memenuhi persyaratan. Data tersebut menunjukkan bahwa penambahan pelet reject sampai dengan 50\% sebagai campuran batubara bahan bakar boiler masih bisa dilakukan dengan kemungkinan terjadinya slagging dan fouling pada saat proses pembakaran rendah (Hatt, 1990; Hiltunen dkk., 2008; www.venusboiler.com/).

\section{c. Suhu Fusi Abu (Ash Fusion Temperature)}

Untuk memprediksi potensi terjadinya slagging dan fouling di dalam boiler selama pembakaran diperlukan juga data suhu fusi abu dari bahan bakar, selain data kadar mineral abu. Hasil uji suhu fusi abu pelet reject, campurannya dan batubara seperti pada Tabel 4 .
Tabel tersebut memperlihatkan bahwa pada kondisi reduksi, batubara memiliki suhu deformasi awal (DT) $1.415^{\circ} \mathrm{C}$ dan suhu pelunakannya (ST) $1.460^{\circ} \mathrm{C}$. Campuran pelet reject $(5-$ $50 \%)$ dan batubara $(50-95 \%)$ memiliki suhu deformasi awal (DT) $1.230-1.315^{\circ} \mathrm{C}$ dan suhu pelunakannya (ST) $1.270-1.325^{\circ} \mathrm{C}$. Sedangkan pelet reject nya sendiri memiliki suhu deformasi awal (DT) $1.193^{\circ} \mathrm{C}$ dan suhu pelunakan (ST) $1.243^{\circ} \mathrm{C}$. Dari data tersebut terlihat bahwa pelet reject memiliki suhu pelunakan (ST) yang cukup tinggi $\left(>1.200^{\circ} \mathrm{C}\right)$. Penambahan pelet reject sebesar 5 - 50\% sebagai campuran batubara, walaupun sedikit menurunkan suhu pelunakan (ST) akan tetapi masih memiliki suhu pelunakan (ST) yang masih tinggi $\left(>1.250^{\circ} \mathrm{C}\right)$.

Dari pengamatan lapangan, industri kertas umumnya menggunakan boiler jenis circulating fluidized bed (CFB) dengan suhu tungku pembakarannya sekitar $900^{\circ} \mathrm{C}$ dan boiler jenis chain grate dengan suhu tungku pembakarannya sekitar $1.100^{\circ} \mathrm{C}$. Bila dibandingkan suhu operasi boiler di industri kertas dengan suhu awal deformasi (DT) dan suhu pelunakan (ST) pelet reject, pelet reject masih memiliki suhu awal deformasi (DT) dan suhu pelunakan (ST) di atas suhu operasi boiler di industri kertas. Hal ini menunjukkan bahwa penambahan pelet reject sampai sebanyak 50\% sebagai campuran batubara bahan bakar boiler yang dioperasikan pada suhu $1.100^{\circ} \mathrm{C}$ masih memungkinkan karena suhu pelunakan dari mineral abu pelet reject belum tercapai sehingga tidak akan menyebabkan terjadinya slagging dan fouling di dalam boiler (Hare dkk., 2010).

Tabel 3. Kadar Mineral Abu Pelet Reject, Batubara dan Campurannya

\begin{tabular}{|c|c|c|c|c|c|c|c|c|c|}
\hline \multirow{2}{*}{ No } & \multirow{2}{*}{ Bahan } & \multicolumn{8}{|c|}{ Hasil Analisis (\%) } \\
\hline & & $\mathrm{Fe}_{2} \mathrm{O}$ & $\mathrm{CaO}$ & $\mathrm{MgO}$ & $\mathrm{Na}_{2} \mathrm{O}$ & $\mathrm{K}_{2} \mathrm{O}$ & $\mathrm{SiO}_{2}$ & $\mathrm{Al}_{2} \mathrm{O}_{3}$ & $\mathrm{TiO}_{2}$ \\
\hline 1 & Pelet reject & 33,4 & 21,5 & 1,43 & 0,72 & 0,57 & 21,0 & 14,2 & 4,06 \\
\hline 2 & Batubara $95 \%+$ Pelet reject $5 \%$ & 8,96 & 2,74 & 0,94 & 0,56 & 2,01 & 55,1 & 26,1 & 1,25 \\
\hline 3 & Batubara $90 \%$ + Pelet reject $10 \%$ & 10,49 & 3,91 & 1,00 & 0,70 & 2,18 & 53,5 & 25,5 & 1,50 \\
\hline 4 & Batubara $70 \%+$ Pelet reject $30 \%$ & 9,18 & 6,75 & 0,31 & 0,35 & 0,38 & 51,5 & 23,7 & 1,51 \\
\hline 5 & Batubara $50 \%$ + Pelet reject $50 \%$ & 8,75 & 11,03 & 0,85 & 0,49 & 0,67 & 47,9 & 20,6 & 1,59 \\
\hline 6 & Batubara & 8,01 & 2,25 & 0,87 & 0,97 & 1,62 & 60,3 & 23,6 & 1,07 \\
\hline
\end{tabular}


Tabel 4. Hasil Uji Suhu Fusi Abu Pelet Reject, Campurannya dan Batubara

\begin{tabular}{|c|c|c|c|c|c|c|c|c|c|}
\hline \multirow{2}{*}{ No } & \multirow{2}{*}{ Bahan } & \multicolumn{4}{|c|}{$\begin{array}{c}\text { Kondisi Reduksi } \\
\text { (Reducing Atmosphere) }\end{array}$} & \multicolumn{4}{|c|}{$\begin{array}{c}\text { Kondisi Oksidasi } \\
\text { (Oxidizing Atmosphere) }\end{array}$} \\
\hline & & $\begin{array}{l}\text { DT } \\
\left({ }^{\circ} \mathrm{C}\right)\end{array}$ & $\begin{array}{l}\mathrm{ST} \\
\left({ }^{\circ} \mathrm{C}\right)\end{array}$ & $\begin{array}{l}\mathrm{HT} \\
\left({ }^{\circ} \mathrm{C}\right)\end{array}$ & $\begin{array}{l}\text { FT } \\
\left({ }^{\circ} \mathrm{C}\right)\end{array}$ & $\begin{array}{l}\text { DT } \\
\left({ }^{\circ} \mathrm{C}\right)\end{array}$ & $\begin{array}{l}\mathrm{ST} \\
\left({ }^{\circ} \mathrm{C}\right)\end{array}$ & $\begin{array}{l}\mathrm{HT} \\
\left({ }^{\circ} \mathrm{C}\right)\end{array}$ & $\begin{array}{l}\mathrm{FT} \\
\left({ }^{\circ} \mathrm{C}\right)\end{array}$ \\
\hline 1 & Pelet reject & 1.193 & 1.243 & 1.258 & 1.300 & 1.203 & 1.253 & 1.273 & 1.325 \\
\hline 2 & $\begin{array}{l}\text { Batubara 95\% + Pelet } \\
\text { reject } 5 \%\end{array}$ & 1.315 & 1.325 & 1.338 & 1.398 & 1.333 & 1.343 & 1.353 & 1.400 \\
\hline 3 & $\begin{array}{l}\text { Batubara } 90 \%+\text { Pelet } \\
\text { reject } 10 \%\end{array}$ & 1.360 & 1.420 & 1.430 & 1.450 & 1.430 & 1.450 & 1.460 & 1.470 \\
\hline 4 & $\begin{array}{l}\text { Batubara } 70 \%+\text { Pelet } \\
\text { reject } 30 \%\end{array}$ & 1.270 & 1.290 & 1.310 & 1.350 & 1.380 & 1.390 & 1.400 & 1.420 \\
\hline 5 & $\begin{array}{l}\text { Batubara } 50 \%+\text { Pelet } \\
\text { reject } 50 \%\end{array}$ & 1.230 & 1.270 & 1.290 & 1.330 & 1.320 & 1.330 & 1.340 & 1.360 \\
\hline 6 & Batubara & 1.415 & 1.460 & 1.470 & 1.495 & 1.465 & 1.495 & $>1.500$ & $>1.500$ \\
\hline
\end{tabular}

Keterangan :

DT $=$ Suhu Deformasi (Deformation Temperature)

ST $=$ Suhu pelunakan (Softening Temperature)

$\mathrm{HT}=$ Suhu Hemisfir (Hemisphere Temperature)

FT $=$ Suhu Alir (Flow Temperature)

\section{KESIMPULAN}

Reject industri kertas berbahan baku kertas sebagian besar komponennya terdiri dari serat berupa potongan kertas sebanyak $50,75 \%$ dan plastik berupa selotif/lakban dan lembaran sebanyak 49,25\% dengan kandungan plastik jenis High Density Polyethylene (HDPE) nya lebih dari 99\%. Pelet reject memiliki nilai kalor tinggi dan kandungan sulfur rendah berpotensi dimanfaatkan sebagai bahan campuran batubara bahan bakar boiler. Persentase penambahan pelet reject sampai sebanyak 50\% ke dalam batubara sebagai bahan bakar boiler yang dioperasikan sampai suhu $1.100^{\circ} \mathrm{C}$ masih memungkinkan tanpa menyebabkan indikasi terjadinya slagging dan fouling di dalam boiler.

\section{UCAPAN TERIMA KASIH}

Penulis mengucapkan terima kasih kepada pimpinan dan rekan-rekan di Balai Besar Pulp dan Kertas (BBPK), dan Badan Pengkajian Kebijakan, Iklim dan Mutu Industri (BPKIMI), Kementerian Perindustrian, atas terlaksananya kegiatan penelitian ini.

\section{DAFTAR PUSTAKA}

Balai Besar Pulp dan Kertas, 2012. Kajian Penggunaan Kertas Daur Ulang (Waste Paper) sebagai Bahan Baku Industri Kertas).

Gavrilescu, D., 2008. Energy from Biomass in Pulp and Paper Mills. Environmental Engineering and Management Journal. Vol.7, No.5, 537-546

Hare N; Rasul M. G.; Moazzem S. 2010. A Review on Boiler Deposition/Foulage Prevention and Removal Techniques for Power Plant. Proceedings of the $5^{\text {th }}$ IASME/ WSEAS International Conference on Energy \& Environment. Wisconsin, USA. 217- 222.

Hatt, R. M., 1990. Fireside Deposites in CoalFired Utility Boilers. Prog.Energy Combust. Sci. Vol.16:235-241

Hiltunen, M., Barisic, V., Zabetta, C. E., 2008. Combustion of Different Types of Biomass in CFB Boilers. Proceedings of the $16^{\text {th }}$ European Biomass Conference. 1 - 6

Kuik, O., 2006. Environmental innovation Dynamic in the Pulp and Paper Industry. European Commission, DG Environment. Institute for Environmental Studies Vrije Universiteit De Boelelaan, Amsterdam, the Netherlands 
Maphala, T., 2008. "Identification of sintering and slagging materials: Characterization of coal, ash and non-coal rock fragments", disertasi, School of Chemical and Metallurgical Engineering, Faculty of Engineering and the Built Environment, University of the Witwatersrand, Johannesburg

Oudi, M., Brammer, J., Hornung, A., Kay, M., 2012. Waste to Power. Tappi Journal, Vol.11, No. 2:55-64.

Nobuyuki, N., Hiroyuki, S., Koji, Y., 2011. CFB Combustion Control System for Multiple Fuels. JFE Technical Report, No. 16.

Thacker, W. E. 2000, Beneficial Use OCC and Poly Reject. Proceeding of 2000 TAPPI International Environmental Conference \& Exhibition. Vol.1: 39 - 53.

Miles, T. R., Baxter, L. L., Bryers, R. W., Jenkins, B. M., Oden, L. L., 1995. Alkali Deposit. Summary Report for National Renewable Energy Laboratory US Department Energy.

Nichols, W. E., Flanders, L. N., 1994. An Evaluation of Pelletizing Technology or How to Convert Trash to Fuel. TAPPI Proceeding of Engineering Conference, 1994:915-921. http://www.fortunacoal.com. Kualitas batubara ditentukan oleh maseral dan mineral matter. (Diakses pada tanggal 8 Desember 2013)

http://www.monroecounty.gov. Plastics Analysis Lab. (Diakses pada tanggal 7 Juni 2013).

http://imambudiraharjo.wordpress.com. Slagging dan Fouling (Diakses pada tanggal 8 Oktober 2013)

http://www.venus-boiler.com/technical_paper. php. Innovatives Solution for Controlling Slagging and Fouling in Coal Fired Coal $B F B C$ and CFBC Boilers (Diakses pada tanggal 8 Desember 2013)

http://www. pelletstove.com. Assessment of Pelletized Biofuels (Diakses pada tanggal 19 September 2012)

http://www.jrpf.g.jp.Waste Plastic Solid Fuel: RPF (Refused Paper and Plastic Fuel) (Diakses pada tanggal 8 Oktober 2013) 